\title{
Impact of individual decision-making styles on marketing information system based decision-making
}

\author{
Alowaidi Mahmoud Ghazi A, Wang $\mathrm{Hu}$ \\ School of Management, Wuhan University of Technology, Wuhan, P.R.China, 430070
}

\begin{abstract}
Marketing information system (MIS) enables data processing and transformation of data into valuable information that results in a more effective decision-making from which companies benefit. However, human aspect is still an influential factor in the decision-making process. We conceptualize a connection between decision-making styles of employees, inherent in their habits and practices, and marketing innovation system based on the decision-making process. Through a detailed literature review, a link between spontaneous, individual, rational and dependent decision-making styles with quality and speed of MIS decision-making has been conceived and constructed. We suggest that decision-making styles influence both quality and speed of the decision-making process. Furthermore, quality and speed of MIS decision-making have a positive influence on radical and incremental marketing innovation. This study enriches the body of literature that focuses on the human-technology interaction and is valuable for companies implementing and using MIS to make business decisions.
\end{abstract}

Key words: Marketing information system, decision-making, decision-making styles, marketing performance, marketing innovation

\section{INTRODUCTION}

The existence of an adequate information system, which would secure data acquisition and analyses, as well as the data transformation into useful information is an essential and crucial condition for a company to function effectively (Jobber and Fahy, 2006). Marketing information system is an efficient tool providing past, present and projected information concerning internal operations and external intelligence (Armstrong and Kotler, 2007). Marketing information system is the fundamental precondition for the successful realization of the research project, i.e. means used by producers to collect information about the needs of the consumers (Fremount, et al., 1970). Marketing information system represents efforts of the companies to provide pertinent decision-making information to marketing managers on a regular basis (Appelgate et al., 1988).

However, before actually proceeding to the decision-making process, it has to be clear that decisionmaking is a conscious human process. To decide means to come to a conclusion by considering various alternatives. According to Fremount et.al., (1970), decision-making is defined as a "conscious human process, involving both individual and society and basing upon value and precise premises, with a choice of one behavioral activity among one or more alternatives with the intention of moving toward some desired state of affairs". Despite minor variations in terminology, it is clear that many of the critics of the narrow view of the role of marketing research are favoring a common notion - "the concept of careful search to generate a flow of ideas and information which will help executives make better decisions."

The reason why we desire to further examine this concept is to see if there is an influence of human characteristics regarding marketing information system based decision-making. We also want to see how human characteristics influence the use of marketing information system. This study has implications for all businesses using marketing information systems or considering introducing the marketing information system in their businesses (McDonald, 1996). In our conceptual study, we have adopted a premise that each individual possesses a "habitual propensity" that differentiates him/her in his/her decision-making style (Scott and Brooks, 1995). Affected by individual's decision-making styles, marketing information system facilitated decision-making is a subject of this research paper. In this study, we put an effort into explaining marketing information system decision-making quality and speed. We also aim to explain potential benefits of the marketing information system in the decision-making process in terms of radical and incremental marketing innovations.

\section{DECISION-MAKING STYLES}

Decision-making styles are important strategies for approaching information system use decision dilemmas which results in decision-making as a crucial aspect of managerial behavior not only in information system use but also in other specific areas. The concept of decision-making style is comparable with individual difference paradigms in which there has been a reawakening of interest 


\section{Alowaidi Mahmoud Ghazi A, Wang $\mathrm{Hu}$ \\ Impact of individual decision-making styles on marketing information system based decision-making}

(Allinson and Hayes, 1996; Riding and Rayner, 2013; Spicer and Sadler-Smith, 2005). Based on the extant literature, a number of propositions have been developed with respect to the proposed relationships shown in the model below. Central to the model are the decision-making styles that are proposed to influence the information system use, and that leads to marketing innovation as an outcome. The review of literature shows that the personal characteristics of the decision-maker influence the decisions made (Allinson and Hayes, 1996). Consequently, the quality and speed of decision is dependent on personal characteristics of decision makers. Scott and Bruce (1995) created types of individual differences in decision-making practices conceptualized as four decision-making styles: spontaneous, rational, intuitive and dependent.

Decision-making style is regarded as a characteristic response that results in "a habit-based propensity to react a certain way in a specific decision context". Our research concept is based on the premise that people react in a way that is characteristic to them in the context of MIS decision-making. Managers and leaders adopt different styles of decision-making based on their personality, the situation they face, the culture of the organization, characteristics of the people they are working with, and the nature of the decision itself (Allinson and Hayes, 1996). All different decision-making styles are determined by various approaches. A rational style emphasizes "a thorough search and logical evaluation of alternatives", and an avoidant style emphasizes "postponing and avoiding decisions". An independent style emphasizes "a search for advice and direction from others", an intuitive style emphasizes "a reliance on hunches and feelings" and a spontaneous style emphasizes "a sense of immediacy and a desire to get through the decision-making process as soon as possible" (Scott and Bruce, 1995).

\section{IMPACT OF DECISION-MAKING STYLES ON INFORMATION SYSTEM USE}

The framework proposes that decision-making style influences information system use in the context of quality and speed at which decisions are made. This eventually impacts marketing innovation. Based on the analyzed literature and according to prior studies, a set of four decision-making styles that are applicable to information system use context were identified. These decision-making styles include spontaneous, rational, intuitive, and dependent styles. A detailed description of the relationship between thee four decision-making styles and information system use constructs toward marketing innovation is provided in the following subsections.

\section{SPONTANEOUS}

Time is regarded as a scarce organizational resource, which makes decision speed an important consideration in organizational decision-making processes, which complements the information system use. Managers (decision makers) prefer time-based results, which are more beneficial for achieving particular objectives. This also indicates flexibility of an organization towards quality and speed of decision and thus lessens organization's exposure to the uncertainties of external environment (Angwin, 2004). Spontaneous decision-making is impulsive and individuals are prone to make "spur-of-themoment" or "instant" decisions. Based on this, we can posit that individuals that fit under spontaneous decision-making style better handle marketing circumstances that require speedy decisions. Individuals in this style are characterized by a feeling of immediacy and the desire to get through the decisionmaking process as quickly as possible (Spicer and Sadler-Smith, 2005). Prior studies on decision speed view prompt action as a decisive competitive weapon for market innovation. Similar studies suggest that decision speed does not lessen decision quality and longer time used to make a decision do not necessarily guarantee or increase decision accuracy (Wilson et al., 1986). Organizations and individuals ability to make such quick decisions is affected by factors within their internal and external environment streamlined toward market innovation. Decision speed achieved by spontaneous decision-making style can be a source of competitive edge in the light of subsequent empirical prescriptions of the pursuit of marketing innovation (Bourgeois and Eisenhardt, 1988). This background discussion brings the development of the following hypotheses;

H1a: Spontaneous decision-making style positively influence decision quality

$\mathrm{H} 1 \mathrm{~b}$ : Spontaneous decision-making style positively influence decision speed

\section{RATIONAL}

Consistent with a Parsonian perspective that argues that decision-making styles are strategies for solving problems, a rational style which encompasses active and well-calculated plans of decision-making activities has been proposed as an ideal strategy (Larson and Gobeli, 1987). Nonetheless, research only partially supports this proposition. Several studies that examined the relationship between a rational style and progress in decision-making on tasks have shown positive or trivial results (Harren et al., 1978; Lunneborg, 1978; Phillips et al., 1984). Individuals that are in rational decision-making style forestall the need to make a decision and prepare for it by seeking relevant information about themselves and their environment before committing to a particular decision. This process has an 


\section{Alowaidi Mahmoud Ghazi A, Wang $\mathrm{Hu}$ \\ Impact of individual decision-making styles on marketing information system based decision-making}

influence on quality of decision made; there is high probability of making an informed quality decision, however, the speed of decision is likely not to be prompt because of the time span required in gathering information. In rational decision-making style, an individual's main approach to gathering the information and processing it to capture only relevant details is systematic and oriented toward both internal and external sources which contributes heavily to decision quality that consequently leads to marketing innovation (Thunihohm, 2004).

The decision makers in rational decision-making style takes time to comprehensively analyze a number of possible alternatives from different scenarios before making a choice. The scenarios are then weighted by probabilities and the decision maker determines the expected outcome or impact of each decision for each alternative. On this basis, the final choice would be for the alternative that presents the finest expected outcome (Oliveira, 2007). Rational decision-making thus presumes that available information enables the decision maker to settle for the best possible alternative. Hence, the rationality is in the essence of selecting which information to order and analyze and which not to (Choo, 2006; Citroen and Hooghoff, 2003; Hussey, 1997; Schwenk, 1986). The decision-making process structured approach is described by the fact that the decision is reached after an extensive search with due attention to a number of distinctive phases that are orderly timed, observed and examined in a rational and objective way. Thus far, we can hypothesize that;

H2a: Rational decision-making style positively influence decision quality $\mathrm{H} 2 \mathrm{~b}$ : Rational decision-making style positively influence decision speed

\section{INTUITIVE}

Intuitive approach to information system use decision-making is primarily based on self-awareness rather than relevant gathered information (Blustein, 1987). According to Phillips et al. (1984), while intuition is likely to include spontaneous decision-making style, an individual feels they have solved a problem or made a decision on the level of control they possess toward solving such a problem or making a decision. The speed of arriving to a decision is rather swift. This is an important scenario of this type of decision-making, necessary for capturing opportunities of strategic windows in the context of marketing innovation. Intuitive decision-making style gained great popularity in recent years although its imprints can be traced back to Chester Barnard (1938). Given that I recent times organizations rely heavily on prompt service delivery, the intuitive approach is regarded as an important factor for speedy decision-making. The role of intuition in decision-making is quite emphasized in literature. It is conceptualized as a two-step process of implicit knowledge in the first stage, which is significant for not only quality but also speed of decision-making. The decision by an intuitive individual type is made based on the outcome (negative and positive) of previous decisions. Made decision will be used to further form and shape explicit knowledge of decision-making by means of the emotional behavior. Additionally, decision maker in this category is personal (Bierman et al., 2005), which is a feature of the body used to make decisions. According to Patton (2003), there are three sources of intuition used by decision makers when they are trying to handle uncertain and volatile situations of decision-making due to rapid and complex changes in the setting. Firstly, it is an elemental response of decision-making which is overseen on decision maker's instinct that produces a subconscious reaction. However, the reactions are usually suitable and applicable to situations that a decision is required to be made. It is inborn and a reaction that cannot be learned. Secondly, general experience involves learning that happens in the normal process of aging in a person's life and in the process of accumulating experience. Finally, focused learning which revolves on learning derives from deliberate effects to develop habits and achieve intuitive reactions. All these affect the decision quality and the speed at which such decisions are made and are a result of these habits and inborn characteristics of the decision-maker. Based on what has been stated above, the following hypotheses are developed;

H3a: Intuitive decision-making style positively influence decision quality $\mathrm{H} 3 \mathrm{~b}$ : Intuitive decision-making style positively influence decision speed

\section{DEPENDENT}

The decision maker in dependent type of decision-making rely on others for the direction and support. Working toward a common goal as a team, this type of decision-making is interpersonal and intrapersonal, is more of a participative decision-making, which results in a more quality decision. Additionally, the decision might not be quick due to reliance and consultation on others before a final decision is made, however, such decision are less likely to be resisted as other individuals are consulted and aware of the possible outcome of the decision. Dependent decision makers always search for advice and guidance from others before making important decisions (Thunholm, 2004). The processing of using or seeking advice and assistance from others captures the social context within which decisions occur with some people preferring to delegate decisions (Finucane et al., 2002; Samsi and Manthorpe, 2011), seek advice, and make decisions with others. Therefore, this decision-making interaction toward 


\section{Alowaidi Mahmoud Ghazi A, Wang $\mathrm{Hu}$ \\ Impact of individual decision-making styles on marketing information system based decision-making}

information system use has an effect on quality of decision and the speed of making a decision is slow but implementation of such decisions on information system use is prompt.

In a dependent style, decision-making accountability is pushed onto external sources, can have a debilitating influence on information system use. Prior studies have revealed that items from the dependent decision-making do not distinguish how or why people involve others. For instance, the decision maker uses advice of other people in making important decisions. Literally, the decision maker rarely take accountability in making important decisions without consulting others. This could indicate seeking information and advice from experts to make the best decision which is crucial for information system use: decision quality. Moreover, the decision maker can delegate decisions to others that are capable of carrying out the information system tasks; the reason for delegation can be attributed to lack of interest or ability. In the information system framework proposed by Chervany et al., decision effectiveness, which includes quality was found as a part of dependent decision-making. We, therefore, develop the following hypotheses;

H4a: Dependent decision-making style positively influence decision quality

H4b: Dependent decision-making style positively influence decision speed

\section{IMPACT OF INFORMATION SYSTEM USE ON MARKETING INNOVATION}

\section{DECISION QUALITY}

Quality of decision from information system use influences marketing innovation. The decision maker evaluates the value of information system and direct it toward desired objectives. The information systems literature is rich in studies on the use of information system as a competitive weapon. These studies indicate importance and crucial role that information system plays in marketing innovation. At the same time, studies in the international business literature have examined the strategic forces affecting competition at a global scale as compared to domestic competition and have shown the differences of competitive forces faced by domestic corporations. It seems, however, that both management information system and the international management literature have recognized the significance of information system use of quality decisions that are derived from the use of quality information as a facilitator for gaining competitive advantage through marketing innovation in the international environment (Deans and Ricks, 1991). According to Jarvenpaa and Ives, information system is needed to drive marketing innovation activities in a global organization's structure and strategy. Therefore, managing quality decisions about marketing information by the means of information system has become one of the most vital elements of driving effective marketing innovation. This is achieved by collecting and distribution of marketing information to the organizational departments and by using it to promote corporate and brand image to potential customers. Quality decision made offer new ways of cultivating internal efficiencies of an organization. Information systems allow dynamic quality decision communication about new trends in marketing on which business strategies can be aligned and directed in order to attain marketing innovation in the quest of competitive advantage.

Hamidi and Safabakhsh (2011) posit that information system - quality based decision on marketing information systems - is important to support marketing management in its decision-making, which can be aimed toward marketing innovation. Besides the importance of information system use - quality decision to the management perspective, it can be an essential tool for the entire marketing organization. Some scholars have classified information system in marketing by the tasks for which they are typically used (Wierenga and Ophuis, 1997). Information system use: decision quality was used by Wierenga and Ophuis to develop a framework of marketing and sales productivity (MSP) systems which comprises of four subsystems, namely, the salesperson productivity tools, direct mail, telemarketing and sales management. This can be viewed as marketing innovation through use of information system, which dictates the realization of quality decision. Therefore, we hypothesize that;

$\mathrm{H} 5 \mathrm{a}$ : Decision quality of information system use positively influence marketing innovation

\section{DECISION SPEED}

In dynamic and rapid changing markets, organizations cannot afford to rely on slow or rather relaxed decision-making process if they ought to achieve market innovation in order to outperform competitors. Therefore, achieving market innovation in such environments requires decisions to be speedy. In the study by Bourgeois and Eisenhardt (1988), the crucial feature of the decision processes were identified in their beneficial effect on organizational performance (i.e. market innovation). Other researchers have investigated how decision speed is shaped by dimensions of personal characteristics of decision makers, decision specific factors and external environment. The decision speed in the twentieth century was affected by time constraints and cost of acquiring information before making a decision (Buchanan and 


\section{Alowaidi Mahmoud Ghazi A, Wang Hu \\ Impact of individual decision-making styles on marketing information system based decision-making}

Connell, 2006). However, the emergence of information system has enabled theorists to make decisions with an adequate amount of information in an enormous speed.

Decision-making process in an organization consists of two facets: reaching a decision and implementing it. Reaching a decision requires some sort of intelligence, which involves information gathering and processing, then designing which involves formulating and analyzing the decision alternatives, and final choice is made based on the judgments of best alternative to select. While the implementation facet includes the strategies essential to implement and create reached decision from the first facet (Harrison, et al.,1995). Review of literature does not show the difference of decision speed between reaching a decision and implementation. However, in this study, decision speed is totally considered as an important variable toward market innovation. The following hypothesis is derived from the above-discussed theory;

H5b: Decision speed of information system use positively influence marketing innovation

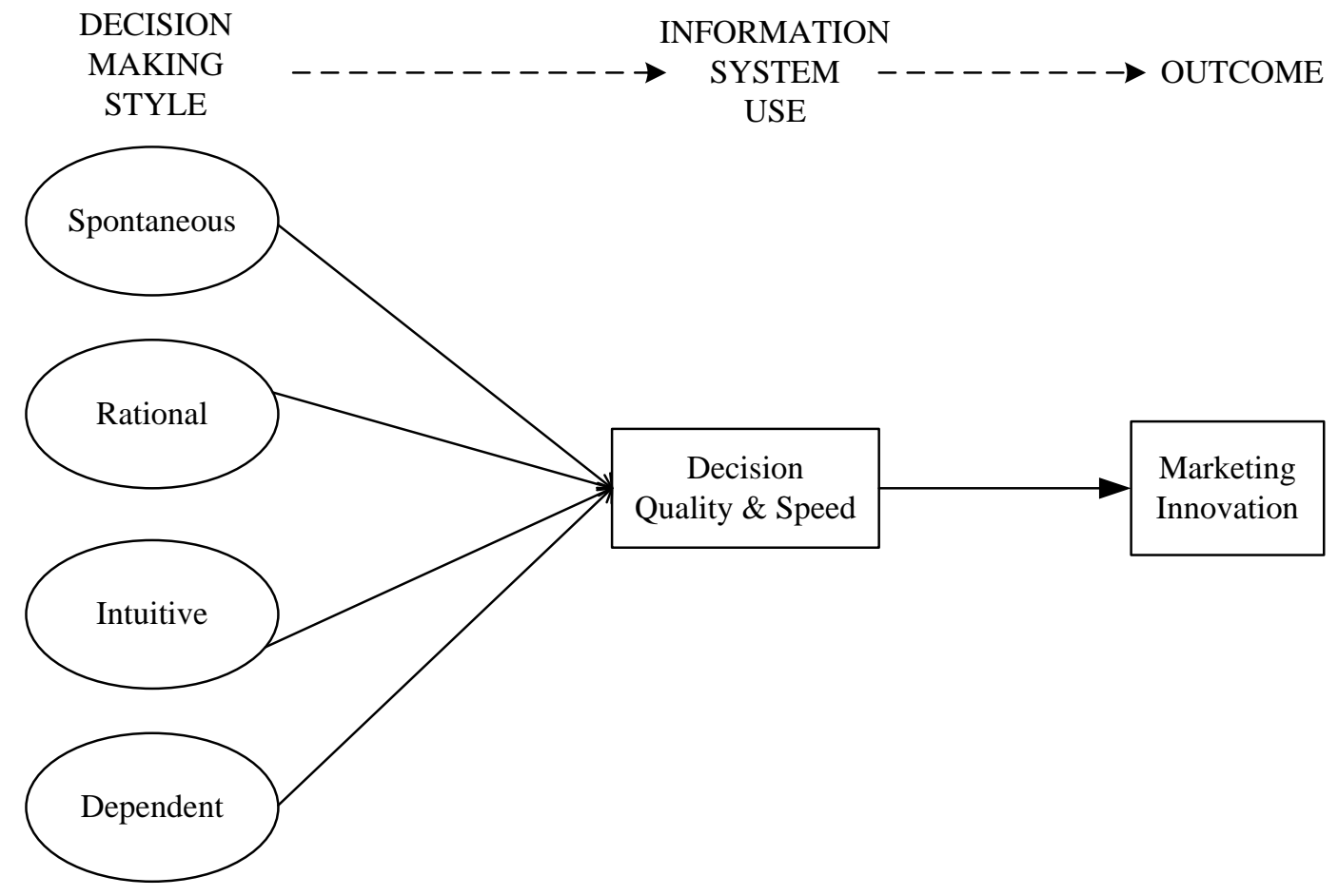

Figure 1: Research model

\section{DISCUSSION AND CONCLUSION}

Through a conceptual discussion, a clear link between decision-making styles and MIS decision-making in terms of quality and speed has been stipulated. Four distinctive decision-making styles may influence MIS based decision-making, as well as the use of MIS. Spontaneous, rational, dependent and intuitive styles of decision-making are all conducive to quality and speed of decision-making. The impact of marketing information systems on decision quality and decision speed is very consistent and important. It shortens the time frame for making decisions, creating a correlation between speed and accuracy (correctness) of a decision and also indicates a lack of efficient or inefficient marketing information system processes. The four decision-making styles must show consistency and order in that ambiguity is minimised in the process of structuring information. Prior studies have examined the relations between decision-making styles and decision-making quality and speed indicating that decision-making styles are able to predict variance in decision-making quality and speed.

Possible implications of the conceptual study exist. Firstly, by introducing a human aspect of decisionmaking into the model, MIS is absolved of the sole responsibility to result in a higher quality and faster decision-making. The function of MIS is valuable in a sense that the information output of the system produces and enables more effective decision-making. However, human aspect is still crucial in the process of making decisions, especially when it comes to decisions that are more complex. It is at that moment that decision-making styles, which stem from individual characteristics of the decision maker, 


\section{Alowaidi Mahmoud Ghazi A, Wang $\mathrm{Hu}$ \\ Impact of individual decision-making styles on marketing information system based decision-making}

may influence the process of decision-making in contrast to when it comes to routine decisions. For instance, an individual characterized by a spontaneous decision-making style is inclined to make impulsive and "instant" decisions. Their desire to get through the decision-making process as quickly as possible (Spicer and Sadler-Smith, 2005) may jeopardize the quality of the decisions made. In order to lessen an impact of the human factor, a marketing information system should be constructed to eliminate the individual differences of decision-makers in terms of their decision-making styles. This can be achieved through an informational output with certain recommendations, suggestions and possible scenarios, as well as decision outcomes.

At the same time, a nature and urgency of the problem should be taken into consideration. With an effective use of MIS, the rational component is added to a decision-making process that may be absent when an individual is characterized by a style other than rational decision-making style. Therefore, an effort can be made to accentuate the rational component given that this particular style is considered to be an ideal decision-making strategy (Larson, 1987). Regardless of the higher quality decision made, collecting relevant information about the environment before committing to a particular decision could result in a time-consuming process, which may not conclude with a satisfactory result if the timeliness presents a factor. Finally, a shared decision can be made. A team of experts can be formed, of various decision-making styles, relying primarily on the output of the MIS to reach a consensus.

When it comes to decision feature impact on marketing innovation, we hypothesize that decision quality and speed affect radical and marketing innovation. Higher quality decisions translate into generation of marketing innovation and it is both the superior processing of data and delivery of output of MIS that facilitate higher quality decision-making. Furthermore, a mediating role of the MIS is hypothesized, meaning that certain decision-making styles translate into marketing innovation through the MIS utilization. MIS should, therefore, be combined with a certain decision-making style in order to produce a desired innovation output.

The study highlighted the role of MIS in decision-making which is still a human process, thus enriching the body of literature focusing on human-technology studies. Furthermore, another concept to measure certain cognitive characteristics of individuals other than decision-making styles can be taken into consideration for further investigating. Cognitive style indicator (Cools and Van den Broeck, 2007), which is similar concept or personality trait influence on MIS based decision-making can also be conceptualized. However, an empirical investigation and a quantitative study to test the conceptual model is suggested. Such study would increase the quality and enrich the diversity of decision-making based on the marketing information system and describe the current condition and state of marketing and business in the context of the study.

\section{REFERENCES}

- Allinson, C., \& Hayes, J. (1996). The cognitive style index. Journal of Management studies, 33(1), 119135.

- Angwin, D. (2004). Speed in M\&A Integration:: The First 100 Days. European Management Journal, $22(4), 418-430$.

- Appelgate, L. M. J. I. Cash and DQ Mills,(1988). Information Technology and Tomorrows managers, Harvard business review, Nov-Dec., pp128-36.

- Bierman, D. J., Destrebecqz, A., \& Cleeremans, A. (2005). Intuitive decision-making in complex situations: Somatic markers in an artificial grammar learning task. Cognitive, Affective, \& Behavioral Neuroscience, 5(3), 297-305.

- Blustein, D. L. (1987). Decision-making styles and vocational maturity: An alternative perspective. Journal of Vocational Behavior, 30(1), 61-71.

- Buchanan, L., \& O Connell, A. (2006). A brief history of decision-making. Harvard Business Review, $84(1), 32$.

- Chervany, N. L., Dickson, G. W., \& Kozar, K. A. (1972). An experimental gaming framework for investigating the influence of management information systems on decision effectiveness. Management Information Systems Research Center, Graduate School of Business Administration, University of Minnesota.

- Choo, C. W. (2006). Information seeking in organizations: epistemic contexts and contests. Information Research, 12(2), 1.

- Citroen, C. L., \& Hooghoff, P. (2003). Informatie in bedrijf: Externe informatie. Informatie in Bedrijf: Werkboek voor succesvol informatiebeheer (Information in the Company: Manual for successful management of information), ISBN, 9-0757.

- Cools, E., \& Van den Broeck, H. (2007). Development and validation of the Cognitive Style Indicator. The Journal of psychology, 141(4), 359-387. 


\section{Alowaidi Mahmoud Ghazi A, Wang $\mathrm{Hu}$ \\ Impact of individual decision-making styles on marketing information system based decision-making}

- Deans, P. C., Karwan, K. R., Goslar, M. D., Ricks, D. A., \& Toyne, B. (1991). Identification of key international information systems issues in US-based multinational corporations. Journal of Management Information Systems, 27-50.

- Eisenhardt, K. M., \& Bourgeois, L. J. (1988). Politics of strategic decision-making in high-velocity environments: Toward a midrange theory. Academy of management journal, 31(4), 737-770.

- Finucane, M. L., Slovic, P., Hibbard, J. H., Peters, E., Mertz, C. K., \& MacGregor, D. G. (2002). Aging and decision- making competence: an analysis of comprehension and consistency skills in older versus younger adults considering health- plan options. Journal of Behavioral Decision-making, 15(2), 141164.

- Fremount, A. S., Delbecg, A. L., \& Cummings, L. L. (1970). Organizational decision-making.

- Hamidi, A., \& Safabakhsh, M. (2011). The impact of information technology on E. marketing. Procedia Computer Science, 3, 365-368.

- Harren, V. A., Kass, R. A., Tinsley, H. E., \& Moreland, J. R. (1978). Influence of sex role attitudes and cognitive styles on career decision-making. Journal of Counseling Psychology, 25(5), 390.

- Hussey, D. (1997). Strategic management: past experiences and future directions: Part 2. Strategic Change, 6(6), 331-344.

- Jarvenpaa, S. L., \& Ives, B. (1993). Organizing for global competition: The fit of information technology. Decision Sciences, 24(3), 547.

- Jobber, D., Fahy, J., \& Kavanagh, M. (2006). Foundations of marketing (pp. 8-9). London: McGraw-Hill Education.

- Kotler, P., \& Armstrong, G. (2010). Principles of marketing. Pearson Education.

- Larson, E. W., \& Gobeli, D. H. (1987). Matrix Management: Contradictions and Insights. California management review, 29(4).

- Lunneborg, P. W. (1978). Sex and career decision-making styles. Journal of Counseling Psychology, 25(4), 299.

- MacDonald, M. L. (1996). A multi-attribute spatial decision support system for solid waste planning. Computers, Environment and Urban Systems, 20(1), 1-17.

- de Oliveira Simonetto, E., \& Borenstein, D. (2007). A decision support system for the operational planning of solid waste collection. Waste Management, 27(10), 1286-1297.

- Patton, J. R. (2003). Intuition in decisions. Management Decision, 41(10), 989-996.

- Phillips, S. D., Pazienza, N. J., \& Walsh, D. J. (1984). Decision-making styles and progress in occupational decision-making. Journal of Vocational Behavior, 25(1), 96-105.

- Priem, R. L., Harrison, D. A., \& Muir, N. K. (1995). Structured conflict and consensus outcomes in group decision-making. Journal of management, 21(4), 691-710.

- Riding, R., \& Rayner, S. (2013). Cognitive styles and learning strategies: Understanding style differences in learning and behavior. Routledge.

- Samsi, K., \& Manthorpe, J. (2011). 'I live for today': a qualitative study investigating older people's attitudes to advance planning. Health \& social care in the community, 19(1), 52-59.

- Schwenk, C. H. (1986). Information, cognitive biases, and commitment to a course of action. Academy of Management Review, 11(2), 298-310.

- Scott, S. G., \& Bruce, R. A. (1995). Decision-making style: The development and assessment of a new measure. Educational and psychological measurement, 55(5), 818-831.

- Spicer, D. P., \& Sadler-Smith, E. (2005). An examination of the general decision-making style questionnaire in two UK samples. Journal of Managerial Psychology, 20(2), 137-149.

- Thunholm, P. (2004). Decision-making style: habit, style or both?. Personality and individual differences, 36(4), 931-944.

- Wierenga, B., \& Ophuis, P. A. O. (1997). Marketing decision support systems: Adoption, use, and satisfaction. International journal of research in marketing, 14(3), 275-290.

- Wilson, D. C., Butler, R. J., Cray, D., Hickson, D. J., \& Mallory, G. R. (1986). Breaking the bounds of organization in strategic decision-making. Human Relations, 39(4), 309-331. 